\title{
Research and Design of Fixed Photovoltaic Support Structure Based on SAP2000
}

\author{
Xingxing Wang ${ }^{1,2}$, Guangjian $\mathrm{Ji}^{1,3}$, Hai Gu${ }^{2}$, Shuaishuai $\mathrm{Lv}^{1,2}$, Hongjun $\mathrm{Ni}^{1,2}$, Ping Wang ${ }^{3}$, Ke Chen ${ }^{1}$, Yue Meng ${ }^{1}$ \\ ${ }^{1}$ School of Mechanical Engineering, Nantong University, Nantong, Jiangsu, 226019, P.R. China \\ 2 Jiangsu Key Laboratory of 3D Printing Equipment and Application Technology, Nantong Institute of Technology, Nantong, Jiangsu \\ 226002, P.R. China \\ ${ }^{3}$ Engineering R \& D Center, Jiangsu Lead Aluminum Co., Ltd, Haian, Jiangsu, 226600, P.R. China
}

\begin{abstract}
In the solar photovoltaic power station project, PV support is one of the main structures, and fixed photovoltaic PV support is one of the most commonly used stents. For the the actual demand in a Japanese photovoltaic power, SAP2000 finite element analysis software is used in this paper, based on Japanese Industrial Standard (JIS C 8955-2011), describing the system of fixed photovoltaic support structure design and calculation method and process. The results show that: (1) according to the general requirements of 4 rows and 5 columns fixed photovoltaic support, the typical permanent load of the PV support is $4679.4 \mathrm{~N}$, the wind load being $1.05 \mathrm{kN} / \mathrm{m}^{2}$, the snow load being $0.89 \mathrm{kN} / \mathrm{m}^{2}$ and the seismic load is $5877.51 \mathrm{~N}$; (2) by theoretical calculation of the two ends extended beam model, the beam span under the rail is determined $2200 \mathrm{~mm}$; (3) by the way of using the single factor experiment, through the calculation and analysis of SAP2000, the three best supporting points of the support of the W stent are determined; (4) by comprehensive simulation, the optimal parameters for the rail, beam, support and bolt are $60 \times 60 \times 1.0,60 \times 60 \times 1.0,40 \times 50 \times 2.0$, and M10 respectively.
\end{abstract}

\section{Introduction}

Solar energy as one of the new energy resources is most widely used currently. In recent years, with the popularization and application of solar photovoltaic support system, the design and development of structure of the photovoltaic support system have also become the focus of attention. At present, the photovoltaic support is mostly steel structure in the market, but the aluminum profile has the characteristics of light weight, beautiful appearance, corrosion resistance and other characteristics, which has attracted the attention of the market [1-4]. Compared with the automatic tracking support, the fixed photovoltaic support has smaller footprint, lower initial investment and less maintenance in the later stage of the support system; In structure, under the same environmental conditions, the stability of the fixed support structure is better than that of the tracking support; In the power generation capacity, the power generation of the tracking support is better than the fixed support, but it needs a longer investment recovery cycle[5-7]. The software SAP2000 has strong functions, such as model (2D, 3D model, etc.), editing function (adding and deleting units, copying and deleting, etc.), analysis function (time history analysis, dynamic analysis), load function (node load, rod load, surface load and temperature load), custom features, and design function etc.
Taking an engineering project in Japan as an example, the SAP2000 software was used in this paper to carry out the analysis and research on the bearing capacity of the fixed photovoltaic support under various load conditions, so as to provide a reference method for the structural design of the fixed photovoltaic support.

\section{Simulation}

\subsection{The basic parameters of project}

A project was located in Kaseda City Jinfeng town of Japan. The degree of the design angle of PV modules was 15 , and the PV module specification was $1650 \mathrm{~mm}$ $\times 991 \mathrm{~mm} \times 40 \mathrm{~mm}$. The single photovoltaic array unit was composed of 20 photovoltaic modules, which were arranged into 4 rows and 5 columns. According to the design requirements of power station, in the photovoltaic support design process, the array structure strength should meet the environmental requirements, such as the wind load $1.05 \mathrm{kN} / \mathrm{m}^{2}$, the snow load $0.89 \mathrm{kN} / \mathrm{m}^{2}$, and the basic parameters were shown in table 1 .

\subsection{Design of overall scheme}

(1) Design of photovoltaic support structure 
According to the 4 rows and 5 columns PV modules of the fixed photovoltaic support overall requirements, combined with the project development experience, the triple-layer composite of photovoltaic support were rail, beam, and column; The conventional screw pile was used in the foundation part; At the same time, the rail and beam length were determined which were $8390 \mathrm{~mm}$ and $4300 \mathrm{~mm}$; There were 5 rails arranged on the upper and lower ends of the PV module; The beam was vertically arranged at the underside of the rail, and the number and span of the beam needed to design and optimize; The type of the pillar arranged below the beam was W, and the 3 contact points of the beam needed to design and optimize.

Table 1. Parameters of PV module and design requirements of PV support

\begin{tabular}{cc}
\hline Parameter type & Parameter values \\
\hline Module size & $1650 \mathrm{~mm} \times 991 \mathrm{~mm} \times 40 \mathrm{~mm}$ \\
Module weight & $19 \mathrm{~kg}$ \\
Module surface area \\
$\begin{array}{c}\text { Mounting angle of PV } \\
\text { support } \alpha \\
\text { Module height from } \\
\text { the ground }\end{array}$ & $1.63515 \mathrm{~m}^{2}$ \\
\hline
\end{tabular}

(2) Lightweight design of photovoltaic stent

The commonly used sections of rail, beam, and column were $60 \times 60,60 \times 60$, and $40 \times 50$, and various thickness specifications could be selected. The photovoltaic support section could be seen in figure 1 . The overall scheme of photovoltaic support structure and the type of section of the main profile were determined, and reducing the amount of aluminum material of the photovoltaic support was the main goal of lightweight design, under the premise of ensuring the structural strength of the photovoltaic support. Using the method of layer by layer design and verification discussed the effects on bearing capacity of the rail and beam with different thickness sections, and provided a basis for the selection of reasonable economic profile.

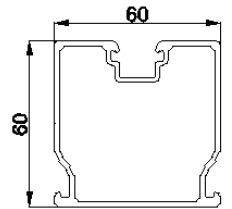

(a)Rail

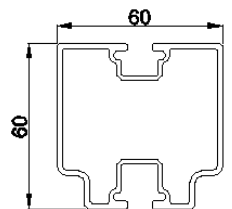

(b)Beam

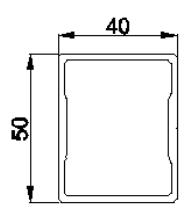

(b)Column
Figure 1. Section of photovoltaic support profiles

\subsection{Method of simulation}

(1) According to the design guide on structures for photovoltaic array (Japanese Industrial Standard, JIS C 8955-2011), combined with the basic parameters of the project, the typical permanent load, wind load, snow load and seismic load of the photovoltaic support were determined.

(2) According to the two ends of the beam theory, combined with the beam number of designs, the influences of different quantities and span of beam on rail performance were discussed, so as to make sure the number and span of beam.

(3) With the single factor experiment, using SAP2000 software discussed the different support layout effects on the beam performance, so as to make sure the best supporting point position of beam.

(4) When the overall structure scheme was determined, the SAP2000 software was used for further discussion of the effects of different section thickness on the performance of rail and beam. At the same time, the strength of column and bolt was checked, and it provided the basis for the lightweight photovoltaic support structure design.

\section{Analysis and discussion of results}

\subsection{Analysis and determination of PV stent load}

The load of photovoltaic stent consisted of two parts, the permanent load and live load respectively. The permanent load $(G)$ included the weight of photovoltaic module $\left(G_{l}\right)$, rail weight $\left(G_{2}\right)$, beam weight $\left(G_{3}\right)$. The live load included wind load $(W)$, snow load $(S)$, and seismic load $(K)$, and the load combination classification was shown in table 2 [8-11].

Table 2. Classification of load combinations

\begin{tabular}{|c|c|c|c|}
\hline \multirow{2}{*}{ Load condition } & \multicolumn{2}{c|}{ Distinguishing } \\
\cline { 2 - 4 } & General area & Snowy area \\
\hline Long-term & The usual & $G$ & $G+0.7 S$ \\
\hline \multirow{4}{*}{ Short-term } & Snow & $G+S$ & $G+S$ \\
\cline { 2 - 4 } & Storm & $G+W$ & $G+W$ \\
\cline { 2 - 4 } & & & $G+0.35 S+W$ \\
\cline { 2 - 4 } & Earthquake & $G+K$ & $G+0.35 S+K$ \\
\hline
\end{tabular}

The permanent load was mainly composed of the weight of PV module, rail and beam and the thickness of each was $2 \mathrm{~mm}$. The total load was set as follow.

$$
G=G_{1}+G_{2}+G_{3}
$$

Wind load $\mathrm{W}$ was related to wind force coefficient $C_{w}$, design speed pressure $q_{p}$ and the area of modules $A_{w}$. In actual situation, the PV modules were divided into two cases: downwind load $\left(W_{+}\right)$and upwind load $\left(W_{-}\right)$. By calculation, two kinds of wind load value could be gotten.

$$
\begin{aligned}
& W_{+}=C_{w^{+}} \times q_{p} \times A_{W} \\
& W_{-}=C_{w^{-}} \times\left(-q_{p}\right) \times A_{W}
\end{aligned}
$$


Snow load was determined by the average unit load of snow $P$, vertical snow cover $Z_{s}$, snow area $A_{s}$ and slope coefficient $C_{s}$. The snow load value was as follow .

$$
S=C_{s} \times P \times Z_{s} \times A_{s}
$$

This project belonged to the general area, so the calculated seismic load was as follow.

$$
K=k_{p} \times G
$$

In which, $k_{p}$ was the design of horizontal seismic degree.

After finding out the permanent load, wind load, snow load and seismic load, the maximum load combination could be obtained according to the combination of the general areas in Table 2.

$$
P_{\max }=G+W=G+\left|W_{+}\right| \times \cos \alpha
$$

Therefore, the uniformly distributed load on the rail was as follow.

$$
q=P_{\max } /((n-1) \times L)
$$

Similarly, the maximum horizontal load combination was as follow.

$$
P_{x}=\left|W_{-}\right| \times \sin \alpha
$$

The maximum combination of load in vertical direction was as follow.

$$
P_{z}=G+\left|W_{+}\right| \times \cos \alpha
$$

Among them, $N$ - rail number, $L$ - rail length $(\mathrm{mm})$.

In summary, according to the basic parameters provided by the project, combined with the above formula and the design guide on structures for photovoltaic array JIS C 8955-2011, the calculation results were shown in table 3 .

Table 3. Key parameters of the photovoltaic stent load

\begin{tabular}{ccc}
\hline Name & Code & Parameter (N) \\
\hline Permanent load & $G$ & 4679.4 \\
Downwind load & $W_{+}$ & 30925.5 \\
Upwind load & $W_{-}$ & -37426 \\
Snow load & $S$ & 27933.6 \\
Earthquake load & $K$ & 5877.51 \\
$\begin{array}{c}\text { Maximum load } \\
\text { combination } \\
\text { combination }\end{array}$ & $P_{\max }$ & 36244.8 \\
$\begin{array}{c}\text { Maximum load in } \\
\text { horizontal direction } \\
\text { Maximum load in } \\
\text { vertical direction }\end{array}$ & $P_{x}$ & 9686.5 \\
\hline
\end{tabular}

\subsection{Optimization of beam span}

The known PV module specification was $1650 \mathrm{~mm} \times$ $991 \mathrm{~mm} \times 40 \mathrm{~mm}$, and the modules were arranged in 4 rows and 5 columns. Each module had a horizontal distance of $10 \mathrm{~mm}$, and the rail end was $50 \mathrm{~mm}$ away from the edge of the module, so the rail length was $5 \times 1650+50 \times 2+10 \times 4=8390 \mathrm{~mm}$. According to the two ends extended beam model of material mechanics (Figure
2 (a))[12], the PV support force was simplified into uniform load. The photovoltaic stent could be simplified into a multi fulcrum supporting beam whose ends were extended (Figure 2 (b)). The rail was divided into 2 sections $l_{1}$ and $N$ of $l_{2}$, and the model was symmetrical distribution.

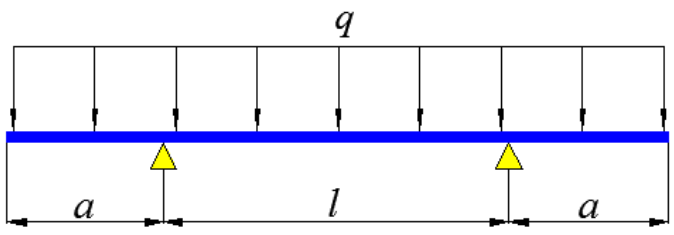

(a) The two ends extended beam model of material mechanics

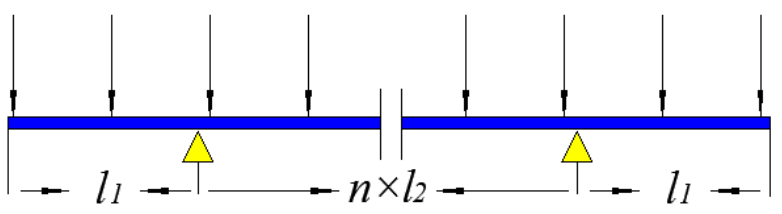

(b)Simplified model of rail with multi fulcrum supporting

Figure 2. Stress model

According to the maximum deflection formula of static perturbation based on the two ends extended beam model[13], if the deformation of the two ends extended beam model was minimum, it could be seen that the relationship between the parameters $a$ and $l$ could be obtained just only when the $W_{\max }$ was zero, here $l \approx 2.19 a$.

$$
W_{\max }=\frac{q I^{4}}{384 E I}\left(5-24 \frac{a^{2}}{l^{2}}\right)
$$

Based on the above relationship, when deformation of $l_{1}$ was equal to $l_{2}$, the stent deformation tended to be coordinated, and it would not appear a part of the deformation which was too large to avoid increasing the section size or thickness, saving materials and reducing cost. According to the relationship between $a$ and $l$ when the deformation was minimum of the two ends of the beam model, the specific parameters of the number of different span beam had been discussed, as shown in table 4.

Table 4. The number of the corresponding parameters of different span beam

\begin{tabular}{ccc}
\hline $\begin{array}{c}\text { Number of } \\
\text { oblique beam }\end{array}$ & $\boldsymbol{l}_{\boldsymbol{1}}(\mathbf{m m})$ & $\boldsymbol{l}_{\mathbf{2}}(\mathbf{m m})$ \\
\hline 2 & 2002 & 4385 \\
3 & 1315 & 2880 \\
4 & 979 & 2144 \\
5 & 780 & 1708 \\
6 & 648 & 1419 \\
\hline
\end{tabular}

When the number of beam was greater than 4 , the span of rail was too small and wasted materials; when the beam number was 3 , the length of cantilever was too 
large, close to a single block's length; when the number of beam was 1 , the span of rail and cantilever were too large. In summary, the number of beam was 4 , and the rail span and cantilever were $2200 \mathrm{~mm}, 895 \mathrm{~mm}$, as shown in figure 3 .

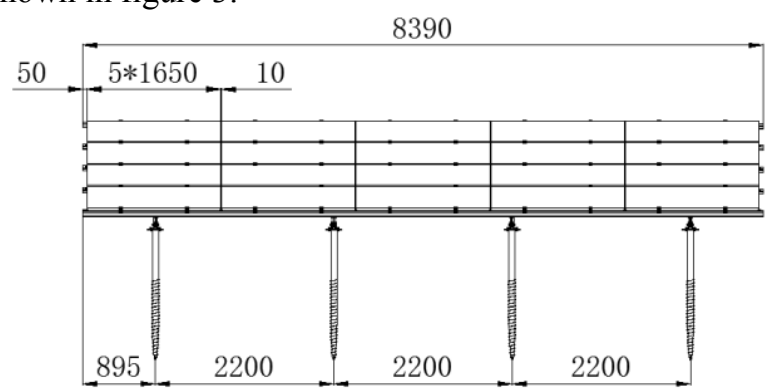

Figure 3. Arrangement of photovoltaic stents

\subsection{Optimization of the position of connection point between beam and column}

The known PV module specification was $1650 \mathrm{~mm} \times$ $991 \mathrm{~mm} \times 40 \mathrm{~mm}$, and the modules were arranged in 4 rows and 5 columns. Each module was longitudinally provided with a pressing block with a $23.5 \mathrm{~mm}$ distance and with a $50 \mathrm{~mm}$ from the end of the beam module edge, so the beam length was $4 \times 991+100 \times 2+23.5 \times 3=4234.5$ $\mathrm{mm}$. The length was $4300 \mathrm{~mm}$ after rounded. The support spacing between beam and pillar was determined by single factor experimental method. With six sets of data, the distance between the support point and the endpoint was $100 \mathrm{~mm}, 200 \mathrm{~mm}, 300 \mathrm{~mm}, 400 \mathrm{~mm}, 500 \mathrm{~mm}, 600$ $\mathrm{mm}$ respectively, using SAP2000 software for simulation, as shown in Figure 4. The structure was symmetrical, so it just needed to monitor two points of contact deformation, and namely the monitoring points were $P_{1}$ and $P_{2}$. And the two monitoring characteristic points were end point $P_{3}$ and span midpoint $P_{4}$ of beam respectively.

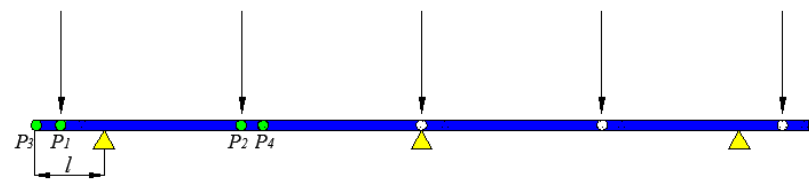

Figure 4. Analysis model of beam

In figure 4, the thickness of beam of the model was 2 $\mathrm{mm}$ and the concentrated load of each point was $500 \mathrm{~N}$. According to the data obtained by SAP2000, statistical analysis was carried out. As shown in fig.5, the deformation tendency of the monitoring point was different when the supporting point spacing $l$ was different. It was shown from the graph that the global average deformation was minimum at $l=400 \mathrm{~mm}$, and the intersection point of deformation track of all monitoring points was between $400-450 \mathrm{~mm}$, so the cantilever support position took $400 \mathrm{~mm}$.

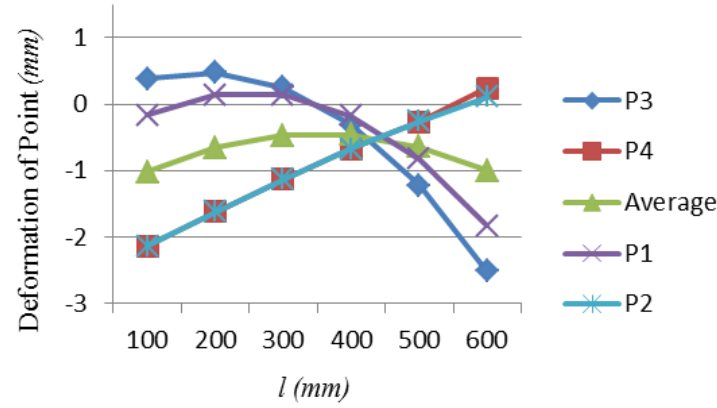

Figure 5. Deformation of monitoring points

\subsection{Lightweight design of guide rail}

On the one hand, the rail should meet the flexibility of the photovoltaic stent specifications $(l / 100, l$-the length of rail's cantilever, $895 \mathrm{~mm}$.), on the other hand, the strength of materials also should meet the requirements. And as known, the yield limit of aluminum profile $\sigma_{\mathrm{s}}$ was 240 $M P a$ and the safety factor was 1.5 , so the $[\sigma]$ was as follow.

$$
[\sigma]=\sigma_{s} / n=160 \mathrm{MPa}
$$

Among them, $N$ - rail number, $L$ - rail length $(\mathrm{mm})$.

According to the engineering experience and the specification of the factory aluminum production, the maximum thickness of the aluminum sections was chosen to carry out the simulation. When the thickness of rail section was $2 \mathrm{~mm}$, the deformation was $4.074 \mathrm{~mm}$ and the maximum stress was $44.697 \mathrm{MPa}$ which met the requirements, and there was a large amount of surplus. Combined with the specific profiles of the company produced section, the calculation and analysis of deformation and the maximum stress value of different section thickness were carried out, then the thickness was optimized. The analysis results were shown in table 5 .

Table 5. Statistics of deformation of rail with different thickness

\begin{tabular}{ccc}
\hline Thickness & Deformation $(\mathrm{mm})$ & Stress $(\mathrm{Mpa})$ \\
\hline $1.0 \mathrm{~mm}$ & 5.801 & 62.595 \\
$1.2 \mathrm{~mm}$ & 5.317 & 57.63 \\
$1.4 \mathrm{~mm}$ & 4.93 & 53.655 \\
$1.6 \mathrm{~mm}$ & 4.602 & 50.244 \\
$1.8 \mathrm{~mm}$ & 4.320 & 47.285 \\
$2.0 \mathrm{~mm}$ & 4.074 & 44.697 \\
\hline
\end{tabular}

From the change rule in table 5, the rail of different section thickness could meet the requirements of the company. From the view of lightweight and material saving, selecting the $1.0 \mathrm{~mm}$ thickness of rail was good. The maximum deformation was $5.801 \mathrm{~mm}<895 / 100$, 
and the stress value was $62.595 \mathrm{MPa}<160 \mathrm{MPa}$, which met the requirements.

\subsection{The lightweight design of beam}

Similarly, the beam also needed to meet the specification of the photovoltaic stents allowable deformation value $(l / 200, l=1750)$ and material strength $([\sigma]=160 \mathrm{MPa})$ requirements like rail.

According to the results of section 3.1, and the number of the beam in section 3.2 was 4 , with the module horizontally placed, the force on the supporting edge of the rail was half of the middle point. So, it would get the rail and beam contact stress formula (3-13) and (3-14).

$$
\begin{gathered}
F_{X}=P_{X} /((n-l) \times N)=605.4 N \\
F_{Z}=P_{Z} /((n-l) \times N)=2234.3 N
\end{gathered}
$$

Among them, $n$ - the number of rail, $N$ - the number of beam.

Figure 6 was the force diagram of the beam structure of photovoltaic support.

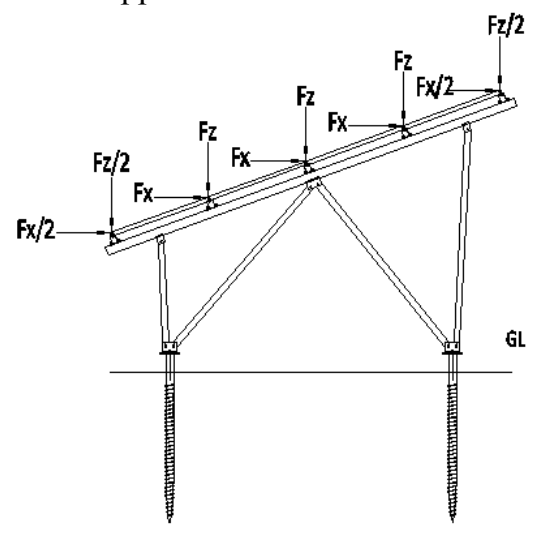

Figure 6. Force diagram of structure

Same as rail, when the thickness of rail section was 2 $\mathrm{mm}$, the deformation was $4.688 \mathrm{~mm}$ and the maximum stress was 67.287 $\mathrm{MPa}$ which met the requirements, and there was a large amount of surplus. Combined with the production of company with specific section, the calculation and analysis of deformation and the maximum stress value of different section thickness were carried out, then the thickness was optimized. The analysis results were shown in table 6 .

From the change rule in table 6 , the rail of different section thickness could meet the requirement of the company. From the view of lightweight and material saving, selecting the $1.0 \mathrm{~mm}$ thickness of rail was good. The maximum deformation was $6.822 \mathrm{~mm}<1750 / 200$, and the stress value was 98.416 $\mathrm{MPa}<160 \mathrm{MPa}$, which met the requirements.

\subsection{Strength inspection of column}

Rail and beam specifications had been determined, and the column specification was $40 \times 50 \times 2$. In the structural model, each column was equivalent to two-force members, and only the axial force was required and checked. According to the force analysis results of the known model in SAP2000, the axial force of each column was shown in table 7.

Table 6. Statistics of beam deformation with different thickness

\begin{tabular}{ccc}
\hline Thickness & Deformation $(\mathrm{mm})$ & Stress $(\mathrm{Mpa})$ \\
\hline $1.0 \mathrm{~mm}$ & 6.822 & 98.416 \\
$1.2 \mathrm{~mm}$ & 6.247 & 89.976 \\
$1.4 \mathrm{~mm}$ & 5.815 & 83.886 \\
$1.6 \mathrm{~mm}$ & 5.455 & 78.781 \\
$1.8 \mathrm{~mm}$ & 4.941 & 70.982 \\
$2.0 \mathrm{~mm}$ & 4.688 & 67.287 \\
\hline
\end{tabular}

Table 7. Statistics of column axial force

\begin{tabular}{cc}
\hline Name & Axial force $(N)$ \\
\hline Front column 1 & 2449.63 \\
Front column 2 & 1864.82 \\
Rear column 1 & 4380.51 \\
Rear column 2 & 2650.52 \\
\hline
\end{tabular}

According to table 7 , the maximum axial force of column was $4380.51 \mathrm{~N}$, and the sectional area of column was $\mathrm{A}=320.46 \mathrm{~mm}^{2}$, so the maximum stress of the column was as follow $[13,14]$.

$$
\sigma=4380.51 / A=4380.51 / 320.46 M p a=13.67 M p a<[\sigma]
$$

Therefore, the strength requirements were met.

\subsection{Bolt strength check}

In the ground fixed support system, the connecting bolts bore the load in the form of shear between column and pile, pillar and beam, pile and beam. The maximum shear force was required to be checked, and it could be seen from table 6 that the value was $4380.51 N$. The model adopted M10 bolt, whose material was Q235 ordinary carbon structural steel, and the yield limit was $215 \mathrm{MPa}$.
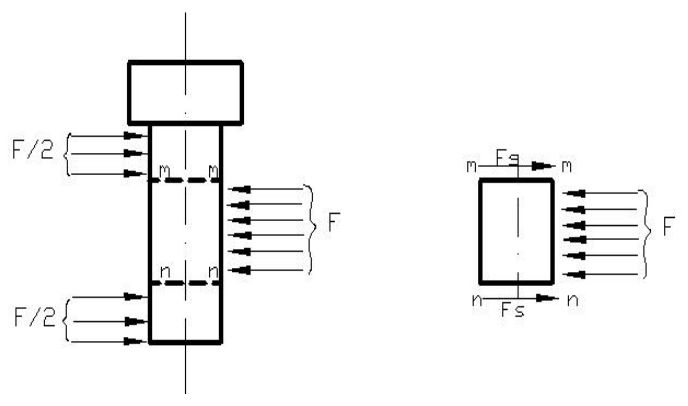

Figure 7. Shear model of bolt 
The shear model of bolt was shown in figure 7 , and $\mathrm{F}$ was the shear force of the bolt. The strength condition was as follow $[15,16]$.

$$
\frac{4 F}{\pi \mathrm{d}^{2} m} \leq[\tau]
$$

In which, $\mathrm{d}$ was diameter of shear surface of bolt; $\mathrm{m}$ was number of bolt shear planes; $[\tau]$ was allowable shear stress of bolt, and the safety factor was 2.5. The shear stress on a single section was as follow.

$$
\frac{4 F}{\pi d^{2} m}=\frac{4 \times 4380.51}{\pi \times\left(10 \times 10^{-8}\right)^{2} \times 4}=13.94 M p a<[\tau]
$$

Therefore, the strength requirements were met.

\section{Conclusion}

In this paper, the load calculation, structural design and optimization, and the strength calculation of the connection parts of the fixed photovoltaic support system are carried out through the actual project case design, which are as follows:

(1)According to the general requirements of the 4 rows and 5 columns fixed photovoltaic stent, the length of the rail is $8390 \mathrm{~mm}$. The initial support profiles thickness is $2 \mathrm{~mm}$, and the typical permanent load of the photovoltaic support is $4679.4 \mathrm{~N}$, the wind load 1.05 $\mathrm{kN} / \mathrm{m}^{2}$, the snow load $0.89 \mathrm{kN} / \mathrm{m}^{2}$ and the seismic load $5877.51 N$.

(2)By the two ends of the beam model of theoretical calculation, comparing the span of the rail and the length of the cantilever when the number of the beam is different, the beam number and rail span are ultimately determined 4 and $2200 \mathrm{~mm}$.

(3) By using the single factor experiment method, through the calculation and analysis of SAP2000, the three best supporting positions of the $\mathrm{W}$ strut are determined.

(4) By the simulation, and the photovoltaic support design requirements, the optimal parameters are for the rail $60 \times 60 \times 1.0$, beam $60 \times 60 \times 1.0$, column $40 \times 50 \times 2$, bolt M10.

\section{Acknowledgements}

This work was financially supported by A Priority Academic Program Development of Jiangsu Higher Education Institutions (PAPD), Jiangsu Policy Guidance Class Program (Industry- University- Research Collaboration) Project (BY2015047-02), Jiangsu Wall Material Innovation Research Project (201702), Frontier and Key Technical Innovation Program of Nantong (MS22015028), Open Fund Project of Jiangsu Key Laboratory of 3D Printing Equipment and Application Technology (Nantong Institute of Technology) (2017KFKT02 、2017KFKT09、2017KFKT10), and Nantong Key Laboratory of 3D printing technology and Application (CP12016002).

\section{References}

1. A. Girard, E. J. Gago, J. Ordoñez, et al, Renewable Energy, 86, 703 (2016).

2. E. Drury, A. Lopez, P. Denholm, et al, Progress In Photovoltaics,22(12), 1302 (2014).

3. H. Khonkar, A. Alyahya, M. Aljuwaied, et al, Solar Energy, 110, 268 (2014).

4. R. R. Hernandez, M. K. Hoffacker, M. L. MurphyMariscal, et al, Proceedings of the National Academy of Sciences, 112 (44), 13579 (2015).

5. X. X. Wang, H. Y. Lu, H. J. Ni et al, AER-Advance in Engineering Research, 22, 297 (2015).

6. H. J. NI, W. F. LU, X. X. Wang et al, AER-Advance in Engineering Research, 22, 302 (2015).

7. C. K. Lin, C. Y. Dai, Wu J C, ReneWable Energy, 59(6), 65 (2013).

8. Japanese Industrial Standard, JIS C 8955-2011 Design guide on structures for photovoltaic array (2011).

9. H. Huang, M. Zhang, Y. T. He. Solar Energy, Chinese, 36(6), 47(2015).

10. B. García-Domingo, M. Torres-Ramírez, J. D. L. Casa, et al, Energy \& Buildings, 83, 130 (2014).

11. Beijing Jintuwu Software Technology Co., Ltd. China Institute of Building Standarddesign \& Research, Guidelines of SAP2000 in Chinese (Beijing: China Communications Press, 2006).

12. Z X. Guo, Static Caculation Handbook for Practical Structure (Beijing: China Machine Press, 2009).

13. H. W. Liu, Static Caculation Handbook for Practical Structure (Beijing: Higher Education Press, 2011).

14. D. X. Cheng, Machine Design Hand Book (Beijing: China Machine Press, 2007)

15. H. Q. Lu, Proceedings of Chinese society for electrical engineering the fifth conference on civil engineering branch of structure (Nanning, China, 2006).

16. Chinese national standards, GB 50797-2012 Design Code for Photovoltaic Power Station (2012). 